\title{
BMJ Open Effect of late-life weight change on dementia incidence: a 10-year cohort study using claim data in Korea
}

\author{
Susan Park, ${ }^{1}$ Soo-Min Jeon, ${ }^{1}$ Sun-Young Jung, ${ }^{2}$ Jinseub Hwang, ${ }^{3}$ Jin-Won Kwon ${ }^{1}$
}

To cite: Park S, Jeon S-M, Jung S-Y, et al. Effect of late-life weight change on dementia incidence: a 10year cohort study using claim data in Korea. BMJ Open 2019;9:e021739. doi:10.1136/ bmjopen-2018-021739

- Prepublication history and additional material for this paper are available online. To view these files, please visit the journal online (http://dx.doi. org/10.1136/bmjopen-2018021739).

SP and S-MJ contributed equally.

Received 15 January 2018 Revised 14 February 2019 Accepted 19 February 2019

Check for updates

(C) Author(s) (or their employer(s)) 2019. Re-use permitted under CC BY-NC. No commercial re-use. See rights and permissions. Published by BMJ.

${ }^{1}$ College of Pharmacy and Research Institute of Pharmaceutical Sciences, Kyungpook National University, Daegu, Republic of Korea

${ }^{2}$ College of Pharmacy, ChungAng University, Seoul, Republic of Korea

${ }^{3}$ Division of Mathematics and Big Data Science, Daegu University, Gyeongsan, Republic of Korea

Correspondence to Professor Jin-Won Kwon; jwkwon@knu.ac.kr

\begin{abstract}
Background The association between body mass index (BMI) in late-life and dementia risk remains unclear. We investigated the association between BMI changes over a 2-year period and dementia in an elderly Korean population.
\end{abstract}

Methods We examined 67219 participants aged 60-79 years who underwent BMI measurement in 2002/2003 and $2004 / 2005$ as part of the National Health Insurance Service-Health Screening Cohort. Baseline characteristics including BMI, socioeconomic status and cardiometabolic risk factors were measured at baseline (2002/2003). The difference between BMI at baseline and at the next health screening (2004/2005) was used to calculate the BMI change. After 2 years, the incidence of dementia was monitored for a mean 5.3 years from 2008 to 2013. Multivariate HRs for dementia incidence were estimated on the basis of baseline BMI and its changes after adjusting for various other risk factors. A subgroup analysis was conducted to determine the effects of baseline BMl and BMl changes.

Results We demonstrated a significant association between late-life BMI changes and dementia in both sexes (men: $>-10 \% \mathrm{HR}=1.26,95 \% \mathrm{Cl} 1.08$ to $1.46,>+10 \%$ $\mathrm{HR}=1.25,95 \% \mathrm{Cl} 1.08$ to 1.45 ; women: $>-10 \% \mathrm{HR}=1.15$, $95 \% \mathrm{Cl} 1.03$ to $1.29,>+10 \% \mathrm{HR}=1.17,95 \% \mathrm{Cl} 1.05$ to 1.31). However, the baseline BMl was not associated with dementia, except in underweight men. After stratification based on the baseline BMI, the BMI increase over 2 years was associated with dementia in men with a BMl of $<25 \mathrm{~kg} / \mathrm{m}^{2}$ and women with a BMl of $18.5-25 \mathrm{~kg} / \mathrm{m}^{2}$, but not in the obese subgroup in either sex. However, BMI decrease was associated with dementia in those with a BMI of $\geq 18.5 \mathrm{~kg} / \mathrm{m}^{2}$, but not in the underweight subgroup in either sex.

Conclusion Both weight gain and weight loss may be significant risk factors associated with dementia. Continuous weight control and careful monitoring of weight changes are necessary to prevent dementia development.

\section{INTRODUCTION}

Dementia is an important health problem with the increase in life expectancy and an ageing population. ${ }^{1}$ In 2015, the World Alzheimer Report noted that 46.8 million people had been diagnosed with dementia and the related global cost was estimated to

\section{Strengths and limitations of this study}

A large cohort data including socioeconomic status, health examination, questionnaires of health behaviours, laboratory data and physician diagnosis.

- Reporting various modifiable risk factors of dementia in late life, such as changes in body mass index, risky health behaviours and uncontrolled diabetes.

- Sensitivity analysis using residual proportional hazard model to check the age effect of age-varying covariates on dementia.

- Some potential confounders, such as educational levels and Apolipoprotein E genotype, could not be adjusted in analysis.

- The accuracy of claim data to identify mild dementia is a known issue.

be US $\$ 818$ billion for that year. ${ }^{2}$ Evidence of the association between cardiometabolic risk factors and dementia has been increasingly reported, ${ }^{3-6}$ and the worldwide prevalence of obesity, which is closely related to cardiometabolic diseases, has increased by $>100 \%$ over the past four decades. ${ }^{78}$ The increasing trend of obesity has recently plateaued in high-income English-speaking countries, while the increasing rate of obesity has accelerated in east and south Asia. ${ }^{78}$ Reducing the risk of dementia is a fundamental strategy to decrease the dementia-related disease burden, because dementia is an irreversible and progressive age-related brain disorder. Therefore, epidemiological studies have focused on modifiable risk factors including obesity and cardiometabolic risk factors such as diabetes, hyperlipidaemia and hypertension. ${ }^{9}$

Based on several meta-analysis and systematic reviews, mid-life obesity has been closely linked to the risk of dementia, particularly with regard to cognitive decline. ${ }^{10-14}$ However, the association between late-life obesity and dementia development has been inconsistent. For example, a preventive effect of being overweight (ie, obesity) on dementia incidence has been reported in several studies, ${ }^{15-17}$ but others have indicated 
the detrimental effect of obesity on dementia. ${ }^{18}$ This discrepancy may be due to weight loss that could lead to confounding with regard to the deleterious effect of adiposity. Unintentional weight loss frequently occurs in the older population, ${ }^{20}$ and it is related to various morbidities including dementia. ${ }^{21-23}$ Thus, a few studies have investigated the effect of later-life body mass index (BMI) and weight change on dementia, but the results were also inconsistent. ${ }^{22-25}$ The majority of such studies did not fully consider the lifestyle and cardiometabolic factors that may influence both weight change and dementia, and the sample size was not sufficient to achieve reliable results.

This study aimed to investigate the associations between BMI and weight change in later life and dementia incidence, after adjusting for the various lifestyle and cardiometabolic risk factors, using a large Korean cohort study.

\section{METHODS}

\section{Study participants}

The National Health Insurance Service-Health Screening Cohort (NHIS-HEALS) is an academic database established by the NHIS, comprising a $10 \%$ random sample $(\mathrm{n}=514866)$ of the national health screening programme in 2002 or 2003 and their insurance administrative data for 10 years from 2002 to 2013 (https://nhiss.nhis.or. $\mathrm{kr} / \mathrm{bd} / \mathrm{ab} / \mathrm{bdaba000eng.do}){ }^{26} \quad$ Approximately $97 \%$ (Medicaid, approximately 3\%) of the Korean population is covered by the NHIS. Health screening is one of the services provided by the NHIS, which involves a biennial medical check-up service for insured people and their dependents aged $\geq 40$ years, and the participation rate of the eligible population in the NHIS health screening programme was $74.8 \%$ in $2014 .{ }^{26}$ The NHIS-HEALS was constructed using the NHIS claim database and the national health screening databases. The NHIS claim database stores information on participants' insurance eligibility details, including the type of health insurance, household income, residential area and demographics, as well as medical treatments including details of prescriptions and diagnosed diseases based on the International Classification of Diseases, 10th Edition (ICD-10). The national health screening database, as a data source of the NHIS-HEALS, contains the results of biennial health examinations such as anthropometric measurements, laboratory data of blood and urine samples, assessment of health behaviours and family history of specific diseases. The national health screening has included a screening test for cognitive decline using the Korean Dementia Screening Questionnaire-Cognitive (KDSQ-C) for 66-year-old examinees since 2008. ${ }^{27}$

We initially selected 132680 participants aged 60-79 years who had their BMI measured at least once in either 2002 or 2003. To exclude the possibility of a time lag prior to detecting dementia, we excluded participants who had a medical history of treatment for dementia from baseline

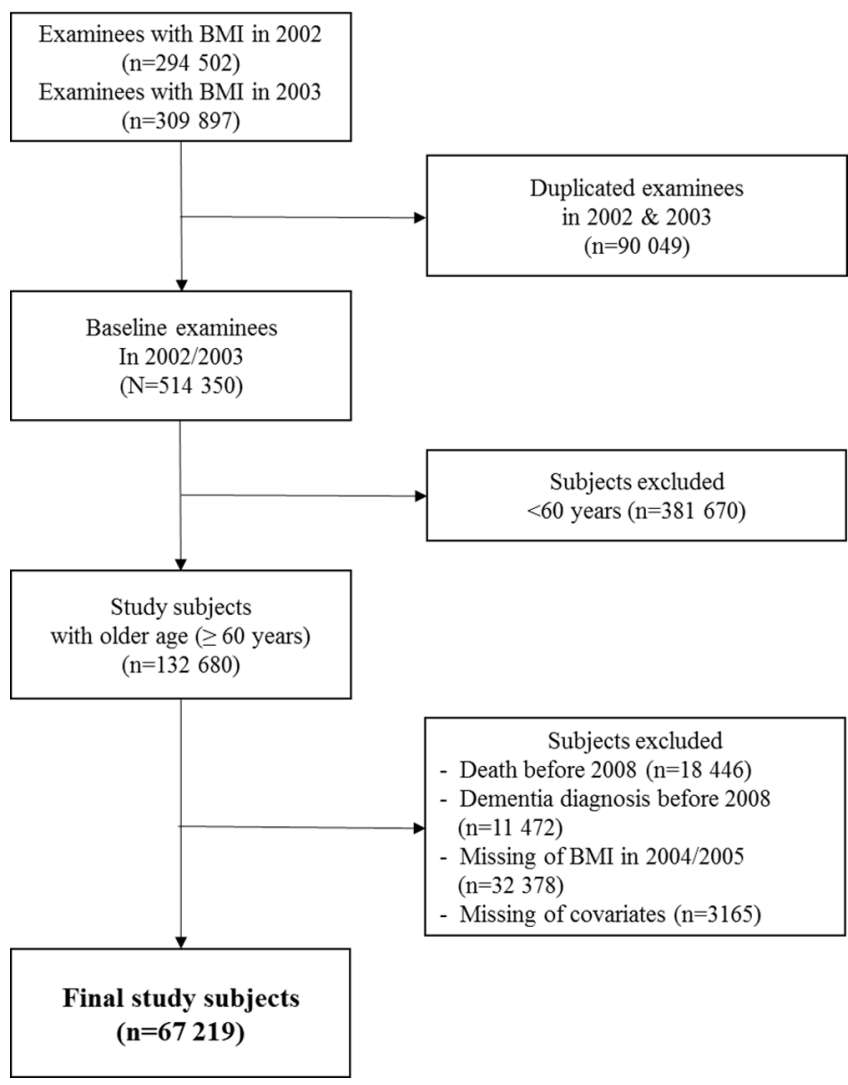

Figure 1 Flow diagram of the subjects included in this study. BMI, body mass index.

(2002/2003) to 2007 ( $\mathrm{n}=11472)$, or who died prior to the follow-up for dementia $(n=18446)$. We also excluded the participants who had not had their BMI measured in 2004 or 2005 for analysis of a 2-year BMI change ( $n=32378)$, or who had missing data regarding the relevant risk factors $(n=3165)$. Finally, 67219 participants were included in this analysis (figure 1 ).

In addition, 15266 subjects who underwent the KDSQ-C in 2009 or 2010 in NHIS-HEALS were used for the subgroup analysis of normal cognitive subjects. After excluding the subjects suspected of cognitive decline (KDSQ-C score of $\leq 4, \mathrm{n}=2165$ ), we analysed 13101 participants.

Informed consent could not be obtained individually because the NHIS-HEALS was released after anonymisation and deidentification of the data.

\section{Measurements}

Physician-diagnosed dementia

Physician-diagnosed dementia was defined as a claim history of the following ICD-10 codes using the insurance administrative data of the NHIS-HEALS: F00 (dementia in Alzheimer's disease), F01 (vascular dementia), F02 (dementia in other diseases classified elsewhere), F03 (unspecified dementia), F051 (delirium superimposed on dementia), G30 (Alzheimer's disease) and G311 (senile degeneration of the brain, not classified elsewhere). 


\section{Body mass index}

The BMI was calculated as the weight in kilograms divided by the square of the height in metres. Height and weight were measured in a standardised manner by trained nurses in each examination site for the biennial check-up. ${ }^{28}$ The baseline BMI was classified into five groups based on the obesity criteria for Asians: $<18.5 \mathrm{~kg} / \mathrm{m}^{2}, 18.5-23 \mathrm{~kg} /$ $\mathrm{m}^{2}, 23-25 \mathrm{~kg} / \mathrm{m}^{2}, 25-30 \mathrm{~kg} / \mathrm{m}^{2}$ and $\geq 30 \mathrm{~kg} / \mathrm{m}^{2}{ }^{29}$ A BMI change over a 2-year period was defined as the difference (percentage) between the baseline BMI (2002/2003) and the remeasured BMI after 2 years $(2004 / 2005)$. The BMI change was categorised into five groups as follows: decrease of $>10 \%$, decrease of $5<-10 \%$, stable $\pm 5 \%$, increase of $5<-10 \%$ and increase of $>10 \%$.

\section{Cardiometabolic risk factors}

A patient with a specific chronic disease was defined as a subject with a claim history of specific diagnostic codes. The ICD-10 codes of the relevant chronic diseases were as follows: atrial fibrillation (I48), congestive heart failure (I43, I50, I099, I110, I130, I132, I255, I420, I425, I426, I427, I428, I429 and P290), diabetes mellitus (DM) (E10-E14) and hypertension (I10). The total cholesterol and fasting plasma glucose levels were categorised into three groups (total cholesterol=optimal $<200 \mathrm{mg}$ / $\mathrm{dL}$, intermediate 200-400 mg/dL and high >400 mg/ $\mathrm{dL}$; fasting plasma glucose $=$ normal $<100 \mathrm{mg} / \mathrm{dL}$, pre-diabetes $100-125 \mathrm{mg} / \mathrm{dL}$, diabetes $\geq 126 \mathrm{mg} / \mathrm{dL}$ ) using laboratory measurements from the national health screening programme. To explore the synergistic effect between fasting blood sugar (FBS) and physician-diagnosed DM, combined variable was created and categorised into four levels: (1) no DM diagnosis and normal/pre-diabetic FBS, (2) no DM diagnosis and diabetic FBS, (3) DM diagnosis and normal/pre-diabetic FBS and (4) DM diagnosis and diabetic FBS.

\section{Health-related behaviours and socioeconomic status}

Health-related behaviours were assessed using self-reported questionnaires completed during the national health screening. Smoking status was categorised as follows: never smoker, past smoker and current smoker.
Frequencies for alcohol consumption and physical activity were grouped as follows: none, less than two times per week and at least three times per week. Household income was divided into three groups (low, middle and high) based on the level of insurance fees in the NHIS insurance eligibility data.

\section{Analysis}

Cox-proportional hazard $(\mathrm{PH})$ models were used to estimate the HRs and 95\% CIs for the associations between various risk factors and dementia. The analysis considered the induction period before the follow-up of dementia incidence to be from baseline $(2002 / 2003)$ to 2007 because weight change has been reported as a symptom of dementia in the early stages. ${ }^{30}$ Thus, follow-up time (in days) was measured from 01 January 2008 until dementia incidence, death, or 31 December 2013. The time point of dementia incidence was defined as the first date of claim history with the diagnosis codes (figure 2).

We considered BMI (baseline and 2-year change) and socioeconomic status (age and household income), health-related behaviours (smoking, alcohol consumption and physical activity) and cardiometabolic risk factors (total cholesterol, hypertension, atrial fibrillation, congestive heart failure and diagnosis of DM and FBS control) to be potential risk factors of dementia in Cox-models. The $\mathrm{PH}$ assumption was checked by the global goodness-of fit test proposed by Schoenfeld, ${ }^{31}$ and no violation of the $\mathrm{PH}$ assumption was observed.

All analyses were performed separately for men and women, because significant interaction effects of baseline BMI and sex on dementia were observed in our data. ${ }^{32} 33$ A stratified analysis using the baseline BMI was conducted to explore the modification of the effect of BMI changes on dementia incidence. In addition, we conducted a subgroup analysis using only the subjects who underwent screening tests for cognitive function to explore the potential effect of mild cognitive impairment on our results.

Statistical analyses were conducted using SAS V.9.4.

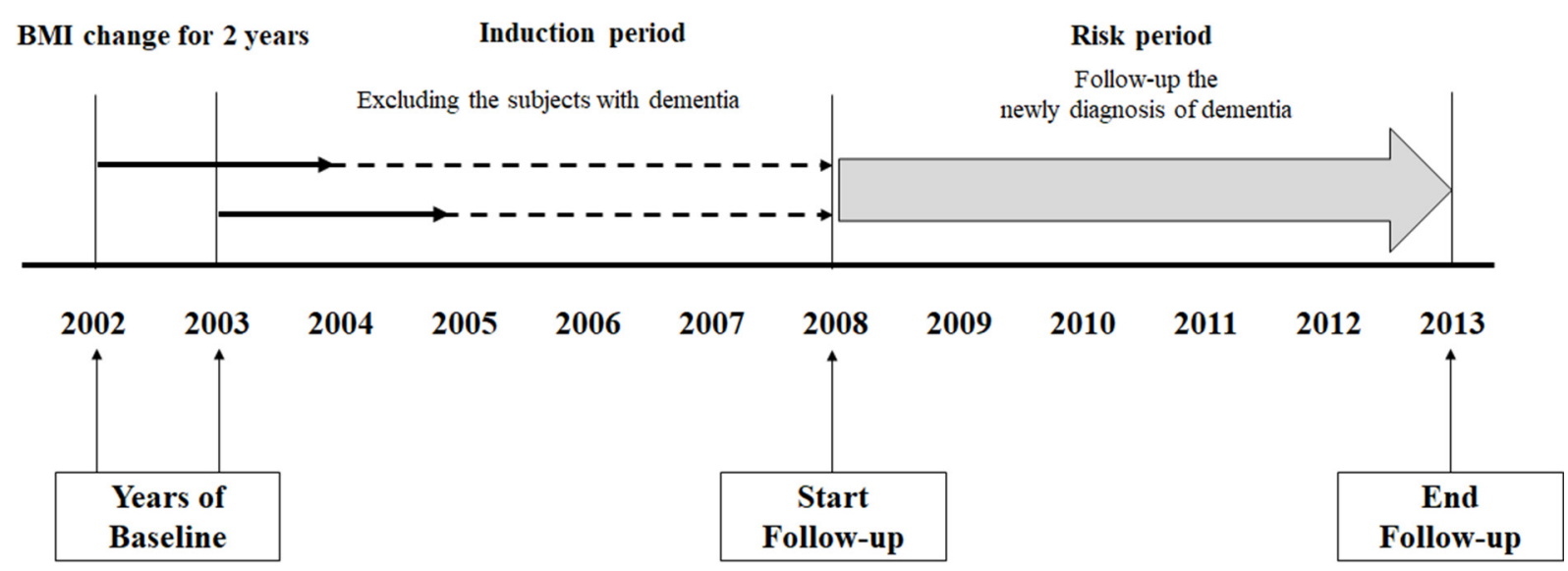

Figure 2 Study timeline for the time point of the dementia follow-up assessment. BMI, body mass index. 


\section{Patient and public involvement}

No patients were involved in developing the research question, outcome measures and overall design of the study. Due to patient anonymity, we are unable to disseminate the results of the research directly to study participants.

\section{RESULTS}

The cohort comprised 67219 participants (men: 34 205; women: 33014 ) and 355640 person-years (men: 180 013; women: 175 627) of follow-up. During the 5.3 years of mean follow-up time, the numbers of men and women with dementia totalled 4887 and 6685 , respectively. The distributions of sex characteristics at baseline are presented in table 1 . The mean age at baseline was approximately 65.4 years in both sexes. Men exhibited a higher prevalence of smoking (men: $30.5 \%$; women: $3.1 \%$ ) and more frequent alcohol consumption (at least three times per week, men: 22.3\%; women: $1.4 \%$ ) than women. The prevalence of high total cholesterol, hypertension and congestive heart failure was higher in women than in men. The proportion of no DM patients with high FBS $(\geq 126 \mathrm{mg} / \mathrm{dL})$ was slightly higher in men $(7.0 \%)$ than in women $(5.3 \%)$, whereas, in DM patients, the proportion of high FBS was similar in both sexes (men: $4.0 \%$; women: $4.1 \%$ ). Patients with atrial fibrillation (men: $1.6 \%$; women: $1.1 \%$ ) were rare in our cohort.

The prevalence of high BMI $\left(\geq 25 \mathrm{~kg} / \mathrm{m}^{2}\right)$ was higher in women $(40.2 \%)$ than in men $(28.9 \%)$. The distribution of the 2-year BMI change was similar in both sexes (BMI increase of $>10 \%, 3.0 \%$ for men, $4.1 \%$ for women; BMI decrease of $>10 \%, 2.9 \%$ for men, $4.1 \%$ for women).

Table 2 presents the univariate and multivariate HRs for dementia incidence according to various risk factors among men. Older age, current smoker, frequent alcohol consumption more than three times a week, hypertension and congestive heart failure were significantly associated with an increased dementia incidence among men. The DM patients with high FBS had an approximately $60 \%$ higher risk of developing dementia than did the subjects with non-DM and normal/prehigh FBS (HR=1.59, 95\% CI 1.41 to 1.81). Regular physical activity (at least three times per week) was associated with a protective effect against the development of dementia. A U-shaped association between BMI change and dementia incidence was characterised by elevated HRs in a $>10 \%$ increase or $>5 \%$ decrease in BMI over 2 years compared with a stable BMI with $\pm 5 \%$ change (BMI decrease of $>10 \%$, $\mathrm{HR}=1.26,95 \%$ CI 1.08 to 1.46 ; BMI decrease of $5<-10 \%$, $\mathrm{HR}=1.19$, 95\% CI 1.09 to 1.29 ; BMI increase of $>10 \%$, $\mathrm{HR}=1.25,95 \%$ CI 1.08 to 1.45$)$. Low BMI $\left(<18.5 \mathrm{~kg} / \mathrm{m}^{2}\right)$ at baseline was associated with an increased dementia risk (HR=1.23, 95\% CI 1.07 to 1.42 ) compared with that associated with a BMI of $23-25 \mathrm{~kg} / \mathrm{m}^{2}$, whereas high BMI at baseline was not associated with dementia development in men $(\mathrm{HR}=0.76,95 \%$ CI 0.57 to 1.01$)$.

The association patterns between risk factors and dementia development in women were generally similar
Table 1 General characteristics of study subjects at baseline $(2002 / 2003)$ by sex

\begin{tabular}{|c|c|c|}
\hline & Men & Women \\
\hline & n (\%) & n (\%) \\
\hline Total & 34205 & 33014 \\
\hline \multicolumn{3}{|l|}{ Age (years) } \\
\hline $60-69$ & 27910 (81.6) & 26797 (81.2) \\
\hline $70-79$ & 6295 (18.4) & $6217(18.8)$ \\
\hline \multicolumn{3}{|l|}{ Income } \\
\hline Low & 6793 (19.9) & $6692(20.3)$ \\
\hline Medium & $14229(41.6)$ & 13205 (40.0) \\
\hline High & $13183(38.5)$ & 13117 (39.7) \\
\hline \multicolumn{3}{|l|}{ Smoking status } \\
\hline Never smoked & $18862(55.1)$ & 31708 (96.0) \\
\hline Past smoker & $4920(14.4)$ & $286(0.9)$ \\
\hline Current smoker & $10423(30.5)$ & $1020(3.1)$ \\
\hline \multicolumn{3}{|l|}{ Drinking status } \\
\hline None & $15852(46.3)$ & 29808 (90.3) \\
\hline$<2$ times per week & 10733 (31.4) & $2749(8.3)$ \\
\hline$\geq 3$ times per week & 7620 (22.3) & 457 (1.4) \\
\hline \multicolumn{3}{|l|}{ Physical activity } \\
\hline None & $19142(56.0)$ & $23894(72.4)$ \\
\hline$<2$ times per week & 6716 (19.6) & $3979(12.1)$ \\
\hline$\geq 3$ times per week & $8347(24.4)$ & $5141(15.6)$ \\
\hline \multicolumn{3}{|l|}{ Total cholesterol } \\
\hline Optimal & $19659(57.5)$ & $13456(40.8)$ \\
\hline Intermediate & $10558(30.9)$ & $12693(38.5)$ \\
\hline High & 3988 (11.7) & $6865(20.8)$ \\
\hline \multicolumn{3}{|l|}{ Hypertension } \\
\hline No & $21465(62.7)$ & $18863(57.1)$ \\
\hline Yes & 12747 (37.3) & $14151(42.9)$ \\
\hline \multicolumn{3}{|l|}{ Atrial fibrillation } \\
\hline No & 33657 (98.4) & 32654 (98.9) \\
\hline Yes & $548(1.6)$ & $360(1.1)$ \\
\hline \multicolumn{3}{|l|}{ Congestive heart failure } \\
\hline No & $32824(96.0)$ & $30878(93.5)$ \\
\hline Yes & $1381(4.0)$ & $2136(6.5)$ \\
\hline \multicolumn{3}{|l|}{ DM diagnosis and FBS* } \\
\hline $\begin{array}{l}\text { No DM diagnosis and } \\
\text { normal/pre-diabetic } \\
\text { FBS }\end{array}$ & $28090(82.1)$ & $27200(82.4)$ \\
\hline $\begin{array}{l}\text { No DM diagnosis and } \\
\text { diabetic FBS }\end{array}$ & $2393(7.0)$ & $1762(5.3)$ \\
\hline $\begin{array}{l}\text { DM diagnosis and } \\
\text { normal/pre-diabetic } \\
\text { FBS }\end{array}$ & $2354(6.9)$ & 2696 (8.2) \\
\hline $\begin{array}{l}\text { DM diagnosis and } \\
\text { diabetic FBS }\end{array}$ & $1368(4.0)$ & $1356(4.1)$ \\
\hline BMI & & \\
\hline
\end{tabular}

Continued 


\section{Table 1 Continued}

\begin{tabular}{|c|c|c|}
\hline & Men & Women \\
\hline & n (\%) & n (\%) \\
\hline$<18.5 \mathrm{~kg} / \mathrm{m}^{2}$ & $1311(3.8)$ & $874(2.7)$ \\
\hline $18.5-23 \mathrm{~kg} / \mathrm{m}^{2}$ & $13482(39.4)$ & $10403(31.5)$ \\
\hline $23-25 \mathrm{~kg} / \mathrm{m}^{2}$ & 9530 (27.9) & $8452(25.6)$ \\
\hline $25-30 \mathrm{~kg} / \mathrm{m}^{2}$ & $9413(27.5)$ & 11959 (36.2) \\
\hline$\geq 30 \mathrm{~kg} / \mathrm{m}^{2}$ & $476(1.4)$ & $1326(4.0)$ \\
\hline \multicolumn{3}{|l|}{ BMI change over 2 years $†$} \\
\hline Decrease of $>10 \%$ & $990(2.9)$ & $1340(4.1)$ \\
\hline Decrease of $5<-10 \%$ & 4006 (11.7) & $4342(13.2)$ \\
\hline Stable at $\pm 5 \%$ & $24934(72.9)$ & $22506(68.2)$ \\
\hline Increase of $5<-10 \%$ & 3252 (9.5) & $3490(10.6)$ \\
\hline Increase of >10\% & $1030(3.0)$ & $1336(4.1)$ \\
\hline
\end{tabular}

*The combination of the physician's diagnosis of DM using an International Classification of Diseases 10th Edition code (E10-E14) and the laboratory data of FBS of $\geq 126 \mathrm{mg} / \mathrm{dL}$ at baseline. †The BMI change over 2 years was calculated as follows: (BMI at baseline-BMI in 2004 or 2005)/BMI at baseline.

BMI, body mass index; DM, diabetes mellitus; FBS, fasting blood sugar.

to those in men (table 3). The risk of dementia was elevated in women of older age; current smokers; and those with hypertension, congestive heart failure, and DM with high FBS. High income and regular physical activity were associated with a decreased risk of dementia in women. Unlike men, women exhibited no association between frequent drinking and dementia. The U-shaped association between 2-year BMI changes and dementia was also observed in women, but the effect sizes of a rapid BMI change were smaller than those in men (BMI decrease of $>10 \%$, HR $=1.15$, 95\% CI 1.03 to 1.29 ; BMI increase of $>10 \%$, HR $=1.17,95 \%$ CI 1.05 to 1.31 ). Neither low body weight nor obesity at baseline were associated with dementia in women.

\section{Survival plots also exhibited}

Table 4 presents the effect of BMI changes on dementia incidence after stratification of the baseline BMI category. The BMI increase over 2 years was associated with dementia risk in men with a BMI of $<25 \mathrm{~kg} / \mathrm{m}^{2}$ (BMI increase of $>10 \%$, underweight group: $\mathrm{HR}=1.48,95 \%$ CI 1.04 to 2.10; normal/overwieght: $\mathrm{HR}=1.24,95 \%$ CI 1.04 to 1.46 ) and women with a BMI of $18.5-25 \mathrm{~kg} / \mathrm{m}^{2}$ (BMI increase of $>10 \%$, HR $=1.2595 \%$ CI 1.10 to 1.43 ), but not in the obese subgroups in both sexes. However, a BMI decrease of $>5 \%$ was associated with dementia incidence in those with a BMI of $\geq 18.5 \mathrm{~kg} / \mathrm{m}^{2}$ but not in the underweight subgroups in both sexes.

Survival plots for men and women also exhibited significant separation according to the 2-year BMI changes (online supplementary figure 1). Our cohort data consisted of participants aged 60-79 years, thus the different age at baseline may exaggerate the impact of age-dependent risk factors, including cardiovascular risk factors, on dementia. To check the modification of age in the impact, we have conducted a sensitive analysis using residual $\mathrm{PH}$ model, which applied the age-at-follow-up as the time scale and age-varying covariates adjusted for age by taking residuals from a regression on age. The result represents that the estimated HRs were similar to those of the main analysis (online supplementary table 1), which implies that the age effect of age-varying covariates was not large in our data. In the subgroup analysis using only subjects who had undergone screening tests for cognitive function, the similar association patterns of 2-year BMI changes on dementia incidence were confirmed after adjusting the KDSQ score in 2009/2010 during the 3-year follow-up (2010-2013). However, the statistical significance had disappeared due to the small sample size (online supplementary table 2 ).

\section{DISCUSSION}

We demonstrated a U-shaped association between a 2-year BMI change and dementia in both sexes. Rapid weight change (ie, a $>10 \%$ increase or decrease in BMI) over a 2-year period was associated with an approximately $20 \%$ higher risk of dementia compared with a stable BMI. However, baseline BMI was not associated with dementia incidence in either sex, with the exception of low body weight in men. The stratified analysis using BMI at baseline revealed a similar U-shaped association between BMI change and dementia in the normal weight subgroup, but the pattern of this association varied in other BMI ranges. Cardiometabolic risk factors including pre-existing hypertension, congestive heart failure, DM and high FBS were significant risk factors for dementia. In particular, DM patients with high FBS had 1.6-fold higher risk of dementia development. Unhealthy lifestyle habits such as smoking, frequent drinking and less physical activity in late life were also associated with dementia.

Our study demonstrated the detrimental effects of weight gain and loss on dementia in an elderly population. Similar to the findings of our study, Luchsinger et al also observed that a weight fluctuation of $1 \mathrm{~kg}$ per year was associated with an approximately $10 \%$ higher risk of dementia than that associated with a stable weight. ${ }^{25}$ Buchman et al found that a 1-unit decrease in BMI was associated with a $25 \%$ increased risk of dementia compared with no change in BMI. ${ }^{22}$ Atti et al also reported that a $>10 \%$ decrease in BMI over a 3-year period was associated with a higher risk of dementia but a BMI increase was not. ${ }^{23}$ Although some studies reported that only weight loss was associated with dementia development, the sample sizes of these studies were not sufficient to explore the effect of weight gain (eg, weight gain subjects, $n=16) .{ }^{23}$

A BMI increase in the elderly could primarily represent an increase in fat mass. ${ }^{34}$ The plasma concentration of inflammatory mediators, such as tumour necrosis factor- $\alpha$ and interleukin 6 , is elevated in individuals with adiposity. ${ }^{35}$ Chronic inflammation could precipitate 
Table 2 HRs for dementia during the 6-year follow-up (2008-2013) according to body weight, socioeconomic status, health behaviours and cardiovascular risk factors at baseline among men

\begin{tabular}{|c|c|c|c|}
\hline & Cases & Univariable model & Multivariable model* \\
\hline & $\mathbf{n}$ & HRs (95\% Cl) & HRs $(95 \% \mathrm{Cl})$ \\
\hline \multicolumn{4}{|l|}{ Body weight } \\
\hline \multicolumn{4}{|c|}{ BMI change over 2 years $\dagger$} \\
\hline Decrease of $>10 \%$ & 177 & 1.45 (1.25 to 1.68$)$ & 1.26 (1.08 to 1.46$)$ \\
\hline Decrease of $5<-10 \%$ & 662 & 1.28 (1.17 to 1.39$)$ & 1.19 (1.09 to 1.29$)$ \\
\hline Stable at $\pm 5 \%$ & 3375 & Ref. & Ref. \\
\hline Increase of $5<-10 \%$ & 480 & 1.11 (1.01 to 1.22$)$ & 1.02 (0.92 to 1.12$)$ \\
\hline Increase of $>10 \%$ & 193 & 1.47 (1.27 to 1.69$)$ & 1.25 (1.08 to 1.45$)$ \\
\hline \multicolumn{4}{|l|}{ BMI } \\
\hline$<18.5 \mathrm{~kg} / \mathrm{m}^{2}$ & 239 & 1.54 (1.34 to 1.77$)$ & 1.23 (1.07 to 1.42$)$ \\
\hline $18.5-23 \mathrm{~kg} / \mathrm{m}^{2}$ & 2049 & 1.16 (1.08 to 1.24$)$ & 1.06 (0.99 to 1.14$)$ \\
\hline $23-25 \mathrm{~kg} / \mathrm{m}^{2}$ & 1293 & Ref. & Ref. \\
\hline $25-30 \mathrm{~kg} / \mathrm{m}^{2}$ & 1257 & 0.98 (0.91 to 1.06$)$ & 1.00 (0.93 to 1.08$)$ \\
\hline$\geq 30 \mathrm{~kg} / \mathrm{m}^{2}$ & 49 & 0.75 (0.56 to 1.00$)$ & 0.76 (0.57 to 1.01$)$ \\
\hline \multicolumn{4}{|l|}{ Socioeconomic status } \\
\hline Age & 4887 & 1.12 (1.11 to 0.00$)$ & 1.11 (1.11 to 1.12$)$ \\
\hline \multicolumn{4}{|l|}{ Income } \\
\hline Low & 944 & Ref. & Ref. \\
\hline Medium & 2012 & 1.01 (0.94 to 1.09 ) & 0.99 (0.92 to 1.07$)$ \\
\hline High & 1931 & 1.04 (0.96 to 1.12$)$ & 0.92 (0.85 to 0.99 ) \\
\hline \multicolumn{4}{|l|}{ Health behaviours } \\
\hline \multicolumn{4}{|l|}{ Smoking status } \\
\hline Never smoked & 2678 & Ref. & Ref. \\
\hline Past smoker & 736 & 1.07 (0.99 to 1.16$)$ & 1.07 (0.98 to 1.16$)$ \\
\hline Current smoker & 1473 & 1.03 (0.96 to 1.09$)$ & 1.10 (1.03 to 1.18$)$ \\
\hline \multicolumn{4}{|l|}{ Drinking status } \\
\hline None & 2333 & Ref. & Ref. \\
\hline$<2$ times per week & 1375 & 0.85 (0.79 to 0.90$)$ & 0.97 (0.91 to 1.04$)$ \\
\hline$\geq 3$ times per week & 1179 & 1.06 (0.99 to 1.14$)$ & 1.11 (1.03 to 1.19$)$ \\
\hline \multicolumn{4}{|l|}{ Physical activity } \\
\hline None & 2961 & Ref. & Ref. \\
\hline$<2$ times per week & 796 & 0.73 (0.67 to 0.79$)$ & 0.85 (0.78 to 0.92$)$ \\
\hline$\geq 3$ times per week & 1130 & 0.85 (0.79 to 0.91$)$ & 0.89 (0.83 to 0.95$)$ \\
\hline \multicolumn{4}{|l|}{ Cardiovascular risk factors } \\
\hline \multicolumn{4}{|l|}{ Total cholesterol } \\
\hline Optimal & 2849 & Ref. & Ref. \\
\hline Intermediate & 1515 & 0.97 (0.91 to 1.03$)$ & 1.03 (0.96 to 1.09$)$ \\
\hline High & 523 & 0.89 (0.81 to 0.97$)$ & 0.94 (0.86 to 1.04$)$ \\
\hline \multicolumn{4}{|l|}{ Hypertension } \\
\hline No & 2817 & Ref. & Ref. \\
\hline Yes & 2070 & 1.29 (1.22 to 1.36$)$ & 1.16 (1.09 to 1.24$)$ \\
\hline \multicolumn{4}{|l|}{ Atrial fibrillation } \\
\hline No & 4789 & Ref. & Ref. \\
\hline Yes & 98 & 1.36 (1.11 to 1.66$)$ & 1.05 (0.86 to 1.29$)$ \\
\hline
\end{tabular}




\begin{tabular}{|c|c|c|c|}
\hline & Cases & Univariable model & Multivariable model ${ }^{*}$ \\
\hline & $\mathbf{n}$ & HRs $(95 \% \mathrm{Cl})$ & HRs $(95 \% \mathrm{Cl})$ \\
\hline \multicolumn{4}{|l|}{ Congestive heart failure } \\
\hline Yes & 260 & 1.46 (1.29 to 1.65$)$ & 1.17 (1.02 to 1.33$)$ \\
\hline \multicolumn{4}{|l|}{ DM diagnosis and FBS $\ddagger$} \\
\hline No DM diagnosis and diabetic FBS & 360 & 1.14 (1.02 to 1.27$)$ & 1.14 (1.02 to 1.27$)$ \\
\hline DM diagnosis and normal/pre-diabetic FBS & 407 & 1.31 (1.19 to 1.45$)$ & 1.25 (1.13 to 1.39$)$ \\
\hline DM diagnosis and diabetic FBS & 271 & 1.56 (1.38 to 1.76$)$ & $1.59(1.41$ to 1.81$)$ \\
\hline
\end{tabular}

${ }^{*}$ All variables were analysed in one model.

†The BMI change over 2 years was calculated as follows: (BMI at baseline-BMI in 2004 or 2005)/BMI at baseline.

$\ddagger$ The combination of the physician's diagnosis of DM using an International Classification of Diseases 10th Edition code (E10-E14) and the laboratory data of FBS of $\geq 126 \mathrm{mg} / \mathrm{dL}$ at baseline.

BMI, body mass index; DM, diabetes mellitus; FBS, fasting blood sugar.

neurodegenerative changes associated with dementia. ${ }^{37} 38$ Thus, increasing fat mass via rapid weight gain might affect dementia development. However, the association between a BMI decrease and dementia might be interpreted as the influence of pre-existing diseases or preclinical symptoms of dementia. Unintentional weight loss is regarded as a symptom of severe disease. ${ }^{39}$ Many chronic diseases, including cardiovascular disease, cancer, liver disease and lung disease, are related to a decline in cognitive function or dementia. ${ }^{40-42}$ An alternative explanation is that weight loss may be a preclinical symptom of dementia. One previous study identified dementia-related symptoms $>6$ years prior to a diagnosis of dementia. ${ }^{43}$

The association between high BMI in later life and dementia is not clear. In our results, a higher BMI at baseline $\left(\geq 25 \mathrm{~kg} / \mathrm{m}^{2}\right)$ was not associated with dementia incidence in either sex. Only a low baseline weight $(<18.5 \mathrm{~kg} /$ $\mathrm{m}^{2}$ ) in men was associated with a significantly increased risk of dementia. These results might be interpreted as a healthy survival effect, as obese people who are vulnerable to many chronic obesity-related diseases are more likely to die before reaching old age. Indeed, obesity is closely related to higher all-cause and cause-specific mortalities in the middle-aged population. ${ }^{4445}$ Therefore, obese elderly people who have survived to the baseline may be more resistant to obesity-related diseases. This pattern was also observed in the results stratified by baseline BMI. In our study, a BMI increase was associated with dementia risk in men of low body weight and women who were of normal weight or who were overweight, but not in the obese subgroup in either sex. Rapid weight gain among non-obese elderly people may place older people at greater risk due to adiposity. An alternative explanation is the limitations associated with BMI measurement. Although BMI is the most commonly used tool to measure obesity in adults, some research has highlighted that BMI alone does not accurately reflect the risk of diseases associated with adiposity. ${ }^{46}$ In addition, age-associated changes in body weight composition may also have influenced our baseline BMI results. ${ }^{48}$

Our results indicated that cardiometabolic risk factors were independently associated with dementia risk in both sexes, which is in line with the findings of previous studies. ${ }^{4040}$ Possible mechanisms that may explain the association include vascular and metabolic processes. Poor vascular condition may lead to brain ischaemia contributing to the development of subcortical white matter lesions, silent infarcts and atrophy. ${ }^{51}$ Metabolic processes, such as insulin levels, may be related to cognitive decline and dementia wherein 'cerebral insulin-resistance' may affect neuronal modulation in cognitive-critical brain areas. ${ }^{52-54}$ In particular, uncontrolled DM was associated with a higher risk of dementia than was controlled DM in our subjects. This finding suggests that the detrimental effect of DM on dementia might be alleviated by effective control of FBS, and that high FBS may be involved in neuronal degeneration processes.

Our results revealed that healthy lifestyle habits in later life were still influential factors of dementia development. Smoking has been reported to be associated with the risk of dementia risk. ${ }^{55}$ Regular physical activity, even low-intensity activity, was associated with reduced risk of dementia. ${ }^{57}$ However, the effect of alcohol consumption was dependent on sex. Alcohol consumption more than three times a week was significantly associated with dementia risk in men, but not in women. Reviews of studies on the effect of alcohol consumption on dementia risk revealed a protective effect of light-to-moderate alcohol consumption, but no significant effect of heavy alcohol consumption. ${ }^{58} 59$ The effect of alcohol depends on the specific alcohol intake in consideration of the beverage type, and frequency and quantity of alcohol consumption. Therefore, future studies should explore the effect of alcohol consumption on dementia based on more detailed calculations in relation to the varieties of alcohol involved in consumption. 
Table 3 HRs for dementia during 6-year follow-up (2008-2013) according to body weight, socioeconomic status, health behaviours and cardiovascular risk factors at baseline among women

\begin{tabular}{|c|c|c|c|}
\hline & Cases & Univariable model & Multivariable model ${ }^{\star}$ \\
\hline & $\mathbf{n}$ & HRs $(95 \% \mathrm{Cl})$ & HRs $(95 \% \mathrm{Cl})$ \\
\hline \multicolumn{4}{|l|}{ Body weight } \\
\hline \multicolumn{4}{|l|}{ BMI change over 2 years $†$} \\
\hline Decrease of $>10 \%$ & 325 & 1.33 (1.18 to 1.48$)$ & 1.15 (1.03 to 1.29$)$ \\
\hline Decrease of $5<-10 \%$ & 943 & 1.16 (1.08 to 1.24$)$ & 1.11 (1.03 to 1.19$)$ \\
\hline Stable at $\pm 5 \%$ & 4347 & Ref. & Ref. \\
\hline Increase of $5<-10 \%$ & 737 & 1.11 (1.03 to 1.20$)$ & 1.07 (0.99 to 1.15$)$ \\
\hline Increase of $>10 \%$ & 333 & $1.38(1.23$ to 1.54$)$ & $1.17(1.05$ to 1.31$)$ \\
\hline \multicolumn{4}{|l|}{$\mathrm{BMI}$} \\
\hline$<18.5 \mathrm{~kg} / \mathrm{m}^{2}$ & 203 & 1.26 (1.09 to 1.45$)$ & 1.07 (0.92 to 1.24$)$ \\
\hline $18.5-23 \mathrm{~kg} / \mathrm{m}^{2}$ & 2215 & 1.10 (1.03 to 1.17$)$ & 1.05 (0.99 to 1.12$)$ \\
\hline $23-25 \mathrm{~kg} / \mathrm{m}^{2}$ & 1672 & Ref. & Ref. \\
\hline $25-30 \mathrm{~kg} / \mathrm{m}^{2}$ & 2338 & 0.98 (0.92 to 1.05$)$ & 0.97 (0.91 to 1.03$)$ \\
\hline$\geq 30 \mathrm{~kg} / \mathrm{m}^{2}$ & 257 & 0.99 (0.87 to 1.13$)$ & 0.92 (0.81 to 1.05$)$ \\
\hline \multicolumn{4}{|l|}{ Socioeconomic status } \\
\hline Age & 6685 & 1.10 (1.09 to 0.00$)$ & 1.09 (1.08 to 1.10$)$ \\
\hline \multicolumn{4}{|l|}{ Income } \\
\hline Low & 1461 & Ref. & Ref. \\
\hline Medium & 2658 & 0.91 (0.85 to 0.97$)$ & 1.00 (0.94 to 1.06$)$ \\
\hline High & 2566 & 0.87 (0.82 to 0.93$)$ & 0.91 (0.85 to 0.97$)$ \\
\hline \multicolumn{4}{|l|}{ Health behaviours } \\
\hline \multicolumn{4}{|l|}{ Smoking status } \\
\hline Never smoked & 6357 & Ref. & Ref. \\
\hline Past smoker & 66 & 1.21 (0.95 to 1.54$)$ & 1.06 (0.83 to 1.36$)$ \\
\hline Current smoker & 262 & 1.38 (1.22 to 1.56$)$ & 1.18 (1.04 to 1.34$)$ \\
\hline \multicolumn{4}{|l|}{ Drinking status } \\
\hline None & 6049 & Ref. & Ref. \\
\hline$<2$ times per week & 542 & 0.96 (0.88 to 1.05$)$ & $1.00(0.92$ to 1.10$)$ \\
\hline$\geq 3$ times per week & 94 & 1.04 (0.85 to 1.27$)$ & 0.95 (0.77 to 1.16$)$ \\
\hline \multicolumn{4}{|l|}{ Physical activity } \\
\hline None & 5064 & Ref. & Ref. \\
\hline$<2$ times per week & 672 & 0.77 (0.71 to 0.83$)$ & 0.84 (0.77 to 0.91$)$ \\
\hline$\geq 3$ times per week & 949 & 0.85 (0.79 to 0.91$)$ & 0.92 (0.86 to 0.99$)$ \\
\hline \multicolumn{4}{|l|}{ Cardiovascular risk factors } \\
\hline \multicolumn{4}{|l|}{ Total cholesterol } \\
\hline Optimal & 2722 & Ref. & Ref. \\
\hline Intermediate & 2554 & 0.99 (0.94 to 1.04$)$ & 1.03 (0.97 to 1.08$)$ \\
\hline High & 1409 & 1.02 (0.95 to 1.08$)$ & 1.05 (0.98 to 1.12$)$ \\
\hline \multicolumn{4}{|l|}{ Hypertension } \\
\hline No & 3378 & Ref. & Ref. \\
\hline Yes & 3307 & 1.37 (1.30 to 1.43$)$ & 1.22 (1.16 to 1.28$)$ \\
\hline \multicolumn{4}{|l|}{ Atrial fibrillation } \\
\hline No & 6598 & Ref. & Ref. \\
\hline Yes & 87 & 1.28 (1.04 to 1.59$)$ & $0.96(0.78$ to 1.19$)$ \\
\hline
\end{tabular}




\begin{tabular}{|c|c|c|c|}
\hline & Cases & Univariable model & Multivariable model $^{*}$ \\
\hline & $\mathbf{n}$ & HRs $(95 \% \mathrm{Cl})$ & HRs $(95 \% \mathrm{Cl})$ \\
\hline \multicolumn{4}{|l|}{ Congestive heart failure } \\
\hline Yes & 567 & $1.44(1.33$ to 1.57$)$ & $1.16(1.06$ to 1.27$)$ \\
\hline \multicolumn{4}{|l|}{ DM diagnosis and FBS $\ddagger$} \\
\hline No DM diagnosis and diabetic FBS & 399 & $1.22(1.11$ to 1.36$)$ & $1.13(1.02$ to 1.25$)$ \\
\hline DM diagnosis and normal/pre-diabetic FBS & 681 & 1.37 (1.27 to 1.49$)$ & 1.29 (1.19 to 1.40$)$ \\
\hline DM diagnosis and diabetic FBS & 376 & 1.55 (1.40 to 1.73$)$ & 1.47 (1.32 to 1.63$)$ \\
\hline
\end{tabular}

*All variables were analysed in one model.

†The BMI change over 2 years was calculated as follows: (BMI at baseline-BMI in 2004 or 2005)/BMI at baseline.

$\ddagger$ The combination of the physician’s diagnosis of DM using an International Classification of Diseases 10th Edition code (E10-E14) and the laboratory data of FBS of $\geq 126 \mathrm{mg} / \mathrm{dL}$ at baseline.

BMI, body mass index; DM, diabetes mellitus; FBS, fasting blood sugar.

This study has several limitations. First, there is some uncertainty regarding the accuracy of the definition of dementia using the ICD-10 codes in the NHIS claims database. Taylor et al noted that $>80 \%$ of Alzheimer's disease and related dementias were identified in 3-year Medicare claims data (using the ICD-9-CM codes). ${ }^{60}$ We used 10-year follow-up claims data from both Medicare and the NHIS. Therefore, an underestimation of the number of patients with dementia is less likely to affect our study. Second, we selected participants who underwent BMI measurement in both 2002/2003 and 2004/2005, which may have caused a selection bias because many participants who took the examination in other years were excluded. However, the distribution of baseline BMI was similar to that in previous Korean reports. ${ }^{61}$ Third, health-related behaviours such as smoking, consuming alcohol and physical activity were defined using self-reported data. The accuracy of self-reported health-related behaviours has been previously explored and has indicated the under-reporting of risky behaviours. ${ }^{62} 63$ This limitation could lead to an underestimation of the effect of health-related behaviour on dementia. Fourth, we could not exclude mild cognitive impairment at baseline. However, we considered a long induction time before the dementia follow-up assessment. Further, we confirmed the similar results in the subgroup analysis without cognitive decline before the follow-up assessment of dementia incidence. Fifth, we could not adjust for the apolipoprotein E genotype and educational level, which are well-known risk factors of dementia, due to lack of information.

Table 4 HRs for the association of the change in body mass index (BMI) with dementia incidence by the baseline BMI category

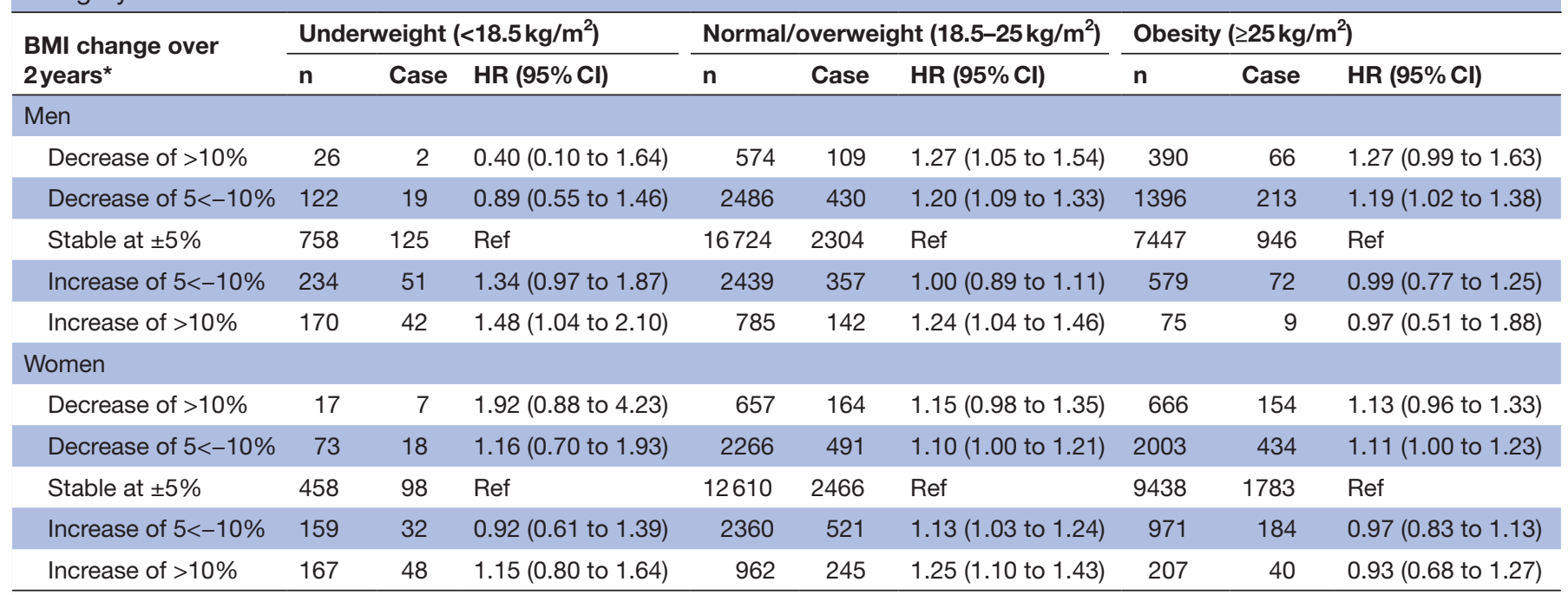

${ }^{*}$ The BMI change over 2 years was calculated as follows: (BMI at baseline-BMI in 2004 or 2005)/BMI at baseline.

†Adjusted for age, household income, smoking, drinking, physical activity, total cholesterol level, atrial fibrillation, congestive heart failure,

diagnosis of diabetes mellitus and fasting blood sugar control and hypertension. 
Nonetheless, our findings have important implications. Using a large cohort dataset, this study revealed that severe weight gain, uncontrolled DM, smoking and less physical activity in late-life had a detrimental effect on dementia development. Our results suggest that continuous weight control, disease management and the maintenance of a healthy lifestyle are beneficial in the prevention of dementia, even in later life. Therefore, a health promotion programme is required that focuses on the modifiable risk factors of dementia and accounts for the health status and physical ageing of the elderly. Investigations into the biological mechanisms of the association between weight change and dementia await future research.

Acknowledgements This study used NHIS-HEALS data (NHIS-2017-2-467) provided by the National Health Insurance Service (NHIS). The authors declare no potential conflicts of interest with NHIS with respect to the authorship and/or publication of this article.

Contributors J-WK took a part in the design of the study. SP and S-MJ analysed the data and wrote the manuscript. S-YJ and JH contributed to revision of manuscript. All authors contributed to interpreting the analyses and to critically revising the article, and approved the final draft.

Funding This research was supported by a grant from the Korea Health Technology R\&D Project through the Korea Health Industry Development Institute (KHIDI), funded by the Ministry of Health \& Welfare, Republic of Korea (grant number: HC15C1322 to Jin-Won Kwon) (http://www.mohw.go.kr). The funders had no role in study design, data collection and analysis, decision to publish, or preparation of the manuscript

Competing interests None declared.

Patient consent for publication Not required.

Ethics approval This study was approved by the Kyungpook National University Institutional Review Board (IRB: KNU 2016-0077).

Provenance and peer review Not commissioned; externally peer reviewed.

Data sharing statement The dataset will be available on request to the NHIS (https://nhiss.nhis.or.kr/bd/ay/bdaya001iv.do).

Open access This is an open access article distributed in accordance with the Creative Commons Attribution Non Commercial (CC BY-NC 4.0) license, which permits others to distribute, remix, adapt, build upon this work non-commercially, and license their derivative works on different terms, provided the original work is properly cited, appropriate credit is given, any changes made indicated, and the use is non-commercial. See: http://creativecommons.org/licenses/by-nc/4.0/.

\section{REFERENCES}

1. Winblad B, Amouyel P, Andrieu S, et al. Defeating Alzheimer's disease and other dementias: a priority for European science and society. Lancet Neurol 2016;15:455-532.

2. Prince MJ, Wimo A, Guerchet MM, et al. World Alzheimer Report 2015: the global impact of dementia: an analysis of prevalence, incidence, cost and trends. London: Alzheimer's Disease International, 2015.

3. Whitmer RA, Sidney S, Selby J, et al. Midlife cardiovascular risk factors and risk of dementia in late life. Neurology 2005;64:277-81.

4. Kivipelto M, Ngandu T, Fratiglioni L, et al. Obesity and vascular risk factors at midlife and the risk of dementia and Alzheimer disease. Arch Neurol 2005:62:1556-60.

5. Anstey KJ, Lipnicki DM, Low LF. Cholesterol as a risk factor for dementia and cognitive decline: a systematic review of prospective studies with meta-analysis. Am J Geriatr Psychiatry 2008;16:343-54.

6. Biessels GJ, Staekenborg S, Brunner E, et al. Risk of dementia in diabetes mellitus: a systematic review. Lancet Neurol 2006;5:64-74.

7. NCD Risk Factor Collaboration (NCD-RisC). Trends in adult bodymass index in 200 countries from 1975 to 2014: a pooled analysis of 1698 population-based measurement studies with 19.2 million participants. Lancet 2016;387:1377-96.
8. NCD Risk Factor Collaboration (NCD-RisC). Worldwide trends in body-mass index, underweight, overweight, and obesity from 1975 to 2016: a pooled analysis of 2416 population-based measurement studies in 128.9 million children, adolescents, and adults. Lancet 2017;390:2627-42.

9. Baumgart M, Snyder HM, Carrillo MC, et al. Summary of the evidence on modifiable risk factors for cognitive decline and dementia: A population-based perspective. Alzheimers Dement 2015;11:718-26.

10. Anstey KJ, Cherbuin N, Budge M, et al. Body mass index in midlife and late-life as a risk factor for dementia: a meta-analysis of prospective studies. Obes Rev 2011;12:e426-37.

11. Beydoun MA, Beydoun HA, Wang Y. Obesity and central obesity as risk factors for incident dementia and its subtypes: a systematic review and meta-analysis. Obes Rev 2008;9:204-18.

12. Kloppenborg RP, van den Berg E, Kappelle LJ, et al. Diabetes and other vascular risk factors for dementia: which factor matters most? A systematic review. Eur J Pharmacol 2008;585:97-108.

13. Sellbom KS, Gunstad J. Cognitive function and decline in obesity. J Alzheimers Dis 2012;30:S89-95.

14. Profenno LA, Porsteinsson AP, Faraone SV. Meta-analysis of Alzheimer's disease risk with obesity, diabetes, and related disorders. Biol Psychiatry 2010;67:505-12.

15. Hughes TF, Borenstein AR, Schofield E, et al. Association between late-life body mass index and dementia: The Kame Project. Neurology 2009;72:1741-6.

16. Fitzpatrick AL, Kuller LH, Lopez OL, et al. Midlife and late-life obesity and the risk of dementia: cardiovascular health study. Arch Neurol 2009;66:336-42

17. Qizilbash N, Gregson J, Johnson ME, et al. BMI and risk of dementia in two million people over two decades: a retrospective cohort study. Lancet Diabetes Endocrinol 2015;3:431-6.

18. Hayden KM, Zandi PP, Lyketsos CG, et al. Vascular risk factors for incident Alzheimer disease and vascular dementia: the Cache County study. Alzheimer Dis Assoc Disord 2006;20:93-100.

19. Gustafson D, Rothenberg E, Blennow K, et al. An 18-year followup of overweight and risk of Alzheimer disease. Arch Intern Med 2003;163:1524-8.

20. McMinn J, Steel C, Bowman A. Investigation and management of unintentional weight loss in older adults. BMJ 2011;342:d1732.

21. Nilsson PM. Is weight loss beneficial for reduction of morbidity and mortality? What is the controversy about? Diabetes Care 2008;31:S278-83.

22. Buchman AS, Wilson RS, Bienias JL, et al. Change in body mass index and risk of incident Alzheimer disease. Neurology 2005;65:892-7.

23. Atti AR, Palmer K, Volpato $\mathrm{S}$, et al. Late-life body mass index and dementia incidence: nine-year follow-up data from the Kungsholmen Project. J Am Geriatr Soc 2008;56:111-6.

24. Stewart R, Masaki K, Xue QL, et al. A 32-year prospective study of change in body weight and incident dementia: the Honolulu-Asia Aging Study. Arch Neurol 2005;62:55-60.

25. Luchsinger JA, Patel B, Tang MX, et al. Measures of adiposity and dementia risk in elderly persons. Arch Neurol 2007;64:392-8.

26. Seong SC, Kim YY, Park SK, et al. Cohort profile: the National Health Insurance Service-National Health Screening Cohort (NHIS-HEALS) in Korea. BMJ Open 2017;7:e016640.

27. Kim HS, Shin DW, Lee WC, et al. National screening program for transitional ages in Korea: a new screening for strengthening primary prevention and follow-up care. J Korean Med Sci 2012;27:S70-5.

28. Pischon T. Commentary: Use of the body mass index to assess the risk of health outcomes: time to say goodbye? Int J Epidemiol 2010;39:528-9.

29. WHO Expert Consultation. Appropriate body-mass index for Asian populations and its implications for policy and intervention strategies. Lancet 2004;363:157-63.

30. Johnson DK, Wilkins CH, Morris JC. Accelerated weight loss may precede diagnosis in Alzheimer disease. Arch Neurol 2006:63:1312-7.

31. Grant S, Chen YQ, May S. Performance of goodness-of-fit tests for the Cox proportional hazards model with time-varying covariates. Lifetime Data Anal 2014;20:355-68.

32. Rocca WA, Mielke MM, Vemuri P, et al. Sex and gender differences in the causes of dementia: a narrative review. Maturitas 2014;79:196-201.

33. Azad NA, Al Bugami M, Loy-English I. Gender differences in dementia risk factors. Gend Med 2007;4:120-9.

34. Newman AB, Lee JS, Visser M, et al. Weight change and the conservation of lean mass in old age: the Health, Aging and Body Composition Study. Am J Clin Nutr 2005;82:872-8. quiz 915-6. 
35. Hak AE, Pols HA, Stehouwer CD, et al. Markers of inflammation and cellular adhesion molecules in relation to insulin resistance in nondiabetic elderly: the Rotterdam study. J Clin Endocrinol Metab 2001;86:4398-405.

36. Makki K, Froguel P, Wolowczuk I. Adipose tissue in obesityrelated inflammation and insulin resistance: cells, cytokines, and chemokines. ISRN Inflamm 2013;2013:1-12.

37. Eikelenboom P, Hoozemans JJ, Veerhuis R, et al. Whether, when and how chronic inflammation increases the risk of developing late-onset Alzheimer's disease. Alzheimers Res Ther 2012;4:15.

38. Leonard BE. Inflammation, depression and dementia: are they connected? Neurochem Res 2007;32:1749-56.

39. Harrington M, Gibson S, Cottrell RC. A review and meta-analysis of the effect of weight loss on all-cause mortality risk. Nutr Res Rev 2009;22:93-108.

40. Xu WL, Qiu CX, Wahlin A, et al. Diabetes mellitus and risk of dementia in the Kungsholmen project: a 6-year follow-up study. Neurology 2004;63:1181-6.

41. Chen TB, Yiao SY, Sun Y, et al. Comorbidity and dementia: A nationwide survey in Taiwan. PLoS One 2017;12:e0175475.

42. Heflin LH, Meyerowitz BE, Hall P, et al. Cancer as a risk factor for long-term cognitive deficits and dementia. $J$ Nat/ Cancer Inst 2005;97:854-6.

43. Bäckman L, Jones S, Berger AK, et al. Cognitive impairment in preclinical Alzheimer's disease: a meta-analysis. Neuropsychology 2005;19:520-31.

44. Flegal KM, Kit BK, Orpana $\mathrm{H}$, et al. Association of all-cause mortality with overweight and obesity using standard body mass index categories: a systematic review and meta-analysis. JAMA 2013;309:71-82.

45. Jee SH, Sull JW, Park J, et al. Body-mass index and mortality in korean men and women. $N$ Engl J Med Overseas Ed 2006;355:779-87.

46. Pischon T, Boeing H, Hoffmann K, et al. General and Abdominal Adiposity and Risk of Death in Europe. N Engl J Med Overseas Ed 2008;359:2105-20.

47. Keum N, Greenwood DC, Lee DH, et al. Adult weight gain and adiposity-related cancers: a dose-response meta-analysis of prospective observational studies. J Natl Cancer Inst 2015;107:djv088.

48. Kyle UG, Genton L, Hans D, et al. Age-related differences in fat-free mass, skeletal muscle, body cell mass and fat mass between 18 and 94 years. Eur J Clin Nutr 2001;55:663-72.

49. Cermakova P, Lund LH, Fereshtehnejad SM, et al. Heart failure and dementia: survival in relation to types of heart failure and different dementia disorders. Eur J Heart Fail 2015;17:612-9.
50. Xu WL, von Strauss E, Qiu CX, et al. Uncontrolled diabetes increases the risk of Alzheimer's disease: a population-based cohort study. Diabetologia 2009;52:1031.

51. Hughes TF, Ganguli M. Modifiable midlife risk factors for latelife cognitive impairment and dementia. Curr Psychiatry Rev 2009;5:73-92.

52. Ekblad LL, Rinne JO, Puukka $P$, et al. Insulin resistance predicts cognitive decline: an 11-year follow-up of a nationally representative adult population sample. Diabetes Care 2017;40:751-8.

53. Gourovitch ML, Kirkby BS, Goldberg TE, et al. A comparison of rCBF patterns during letter and semantic fluency. Neuropsychology 2000;14:353-60.

54. Willette AA, Bendlin BB, Starks EJ, et al. Association of insulin resistance with cerebral glucose uptake in late middle-aged adults at risk for Alzheimer Disease. JAMA Neurol 2015;72:1013-20.

55. Barnes DE, Haight TJ, Mehta KM, et al. Secondhand smoke, vascular disease, and dementia incidence: findings from the cardiovascular health cognition study. Am J Epidemiol 2010;171:292-302

56. Ott A, Slooter AJ, Hofman A, et al. Smoking and risk of dementia and Alzheimer's disease in a population-based cohort study: the Rotterdam Study. Lancet 1998;351:1840-3.

57. Blondell SJ, Hammersley-Mather R, Veerman JL. Does physical activity prevent cognitive decline and dementia?: A systematic review and meta-analysis of longitudinal studies. BMC Public Health 2014:14:510.

58. Anstey KJ, Mack HA, Cherbuin N. Alcohol consumption as a risk factor for dementia and cognitive decline: meta-analysis of prospective studies. Am J Geriatr Psychiatry 2009;17:542-55.

59. Ilomaki J, Jokanovic N, Tan EC, et al. Alcohol consumption, dementia and cognitive decline: an overview of systematic reviews. Curr Clin Pharmacol 2015;10:204-12.

60. Taylor DH, Fillenbaum GG, Ezell ME. The accuracy of medicare claims data in identifying Alzheimer's disease. J Clin Epidemiol 2002;55:929-37.

61. Kim NH, Lee J, Kim TJ, et al. Body mass index and mortality in the general population and in subjects with chronic disease in Korea: a nationwide cohort study (2002-2010). PLoS One 2015;10:e0139924.

62. Newell SA, Girgis A, Sanson-Fisher RW, et al. The accuracy of selfreported health behaviors and risk factors relating to cancer and cardiovascular disease in the general population: a critical review. Am J Prev Med 1999;17:211-29.

63. Connor Gorber S, Schofield-Hurwitz S, Hardt J, et al. The accuracy of self-reported smoking: a systematic review of the relationship between self-reported and cotinine-assessed smoking status. Nicotine Tob Res 2009;11:12-24. 